\title{
Nanoscale Solute Partitioning and Carbide Precipitation in a Multiphase TRIP Steel Analyzed by Atom Probe Tomography
}

\author{
ARUN DEVARAJ $₫,{ }^{1,5}$ ZEREN XU, ${ }^{2}$ FADI ABU-FARHA, ${ }^{2}$ XIN SUN, ${ }^{3}$ \\ and LOUIS G. HECTOR JR. ${ }^{4}$ \\ 1.-Pacific Northwest National Laboratory, P.O. Box 999, Richland, WA 99352, USA. 2.-Auto- \\ motive Engineering, Clemson University, Greenville, SC 29607, USA. 3.-Oak Ridge National \\ Laboratory, 1 Bethel Valley Road, Oak Ridge, TN, USA. 4.-General Motors Global Technical \\ Center, Warren, MI 48092, USA. 5.-e-mail: arun.devaraj@pnnl.gov
}

\begin{abstract}
Nanoscale solute partitioning across multiple constituent phases in a 980grade quenched and partitioned (Q\&P) steel was analyzed using atom probe tomography (APT). The Q\&P process was used to increase the $\mathrm{C}$ content in the retained austenite phase thereby improving its stability under plastic straining. Significant carbon enrichment of austenite was measured with decreased levels of $\mathrm{C}$ in martensite and almost depleted $\mathrm{C}$ content in ferrite, supporting the $\mathrm{C}$ partitioning mechanism in the literature. The APT analysis of retained austenite surrounded by martensite demonstrated a higher amount of $\mathrm{C}$ content compared with retained austenite surrounded by the ferrite phase. Lath and discrete carbide particle precipitation was also observed inside martensite colonies, tying up $\mathrm{C}$ and reducing the total amount of $\mathrm{C}$ available for austenite stabilization. In addition, the partitioning of $\mathrm{Mn}$ and other minor elements was quantitatively investigated by correlating APT and SEM-EBSD. These techniques provide a robust methodology for analyzing nanoscale compositional partitioning in multiphase steels, TRIP steels in particular, which can be used to better explain their microstructure-mechanical property relationships.
\end{abstract}

\section{INTRODUCTION}

Third-generation advanced high-strength steels are typically transformation-induced plasticity (TRIP) steels with microstructures that contain different volume fractions of ferrite, retained austenite, bainite, and martensite produced from various alloying and heat treatment schemes. ${ }^{1}$ In general, the third-generation AHSSs are distinguished from the first-generation low-alloyed AHSSs by virtue of a higher Mn content (e.g., $\sim 2$ wt.\% or greater), have higher strength levels and contain greater amounts of retained austenite by volume fraction. While dislocation plasticity is critical, an additional mechanism of plastic deformation occurs, which is the diffusionless shear transformation of retained austenite $(\gamma)$ into martensite $\left(\alpha^{\prime}\right)$, denoted by $\gamma \rightarrow \alpha^{\prime}$, with plastic straining, or the so-called TRIP effect. $^{2}$ This martensitic transformation delays necking and fracture and leads to exceptional ductility and strength. Recently, a commercial third-generation AHHS processed with a quenching and partitioning (Q\&P) heat treatment has been the subject of several studies aimed at understanding its mechanical properties and martensitic transformation. ${ }^{3-6}$ The Q\&P process increases carbon enrichment of the retained austenite for both ductility and strength enhancements. ${ }^{7-10}$ With an as-received microstructure consisting (primarily) of ferrite $(\alpha)$, tempered martensite $\left(\alpha_{\mathrm{T}}^{\prime}\right)$, and retained austenite, this material has a $980 \mathrm{MPa}$ tensile strength with $18 \%$ total elongation, making it attractive for automotive applications. ${ }^{3,11}$

Correlation of the QP980 microstructure with its mechanical properties will require a quantitative analysis of how solute elements partition across the multiple phases at the nanoscale with high spatial 
resolution. Not only will this information be needed to tune future alloy designs for more challenging applications, it will be needed for development of material constitutive models that accurately represent microstructural effects on macroscale behavior commonly predicted with finite element models. ${ }^{12}$ The presence of light elements, such as $\mathrm{C}$, along with low concentrations (less than $1 \mathrm{wt} . \%$ ) of other solutes in the ferrite and martensite phases, and the submicron size retained austenite islands, makes it very difficult to obtain accurate compositional analysis of all of these phases by conventional methods such as SEM-EDS. This rendered atom probe tomography (APT) the method of choice for the compositional analysis of the individual QP980 phases. APT is a combination of a point projection microscope and time-of-flight mass spectrometer capable of analyzing the nanoscale composition of metallic alloys at 0.2 -nm spatial resolution in three dimensions. ${ }^{13} \mathrm{In}$ this study, we employed APT to analyze the composition of all constituent phases in the QP980 steel, and the results were compared with the current understanding of the influence of the $\mathrm{Q} \& \mathrm{P}$ process on solute partitioning across phases.

\section{EXPERIMENTAL METHODS}

The 1.2-mm-thick QP980 steel sheet was produced with a two-step Q\&P process. ${ }^{11}$ The steel was solutionized in the austenite field above the AC3 temperature and then subjected to intercritical annealing between AC1 and AC3 to generate proeutectoid ferrite. This was followed by water quenching to temperatures between the martensite start and finish temperatures to get only partial transformation of austenite to martensite resulting in the formation of some retained austenite islands embedded in martensite regions. The water quenched steel was subsequently annealed at a low temperature in between the austentization and quenching temperatures to facilitate carbon partitioning predominantly to retained austenite from the martensite regions. Carbon and manganese are added as austenite stabilizers ${ }^{14}$ and $\mathrm{Si}$ is added to retard carbide precipitation.

SEM imaging and electron backscatter diffraction (EBSD) measurements were conducted using a Hitachi SU6600 SEM, and EBSD data were analyzed using the Oxford Channel 5 software. The APT specimens were extracted from specific phase regions identified with EBSD and SEM imaging with a site-specific focused ion beam (FIB) lift-out process. Needle specimens were produced with a Helios NanoLab 600 dual-beam FIB-SEM followed by annular milling. ${ }^{13}$ The APT analysis was conducted using a CAMECA LEAP 4000XHR APT system in pulsed voltage mode with a $20 \%$ pulse fraction, $200 \mathrm{kHz}$ pulse repetition rate, and 0.005 atoms/pulse average detection rate, while the specimen temperature was maintained at $60 \mathrm{~K}$. The APT data were reconstructed and analyzed using the IVAS software 3.6.14.

\section{RESULTS}

The measured chemical composition of the QP980 steel is $0.2(0.91) \mathrm{C}, 1.79(1.78) \mathrm{Mn}, 1.52(2.95) \mathrm{Si}$, 0.039 (0.08) Al, 0.03 (0.03) Cr, $0.014(0.025) \mathrm{P}, 0.004$ $(0.016) \mathrm{N}$, and $0.003(0.012) \mathrm{S}$ (numbers outside the brackets are in wt.\% and at.\% inside the brackets). ${ }^{3}$ Figure 1a shows a SEM backscattered electron (BSE) image (band contrast image) of the QP980 microstructure. The large grains are ferrite, and the needle-like regions are martensite; austenite is noted as small isolated islands within the ferrite grains or along the boundaries between the ferrite and martensite grains. The corresponding EBSD phase map of the SEM image in Fig. 1a is provided in Fig. $1 \mathrm{~b}$, showing the retained austenite islands with coloring based on their orientation. Both ferrite and martensite are colored white in the EBSD map. The measured area fraction of retained austenite based on Fig. $1 \mathrm{~b}$ is $6.8 \%$, excluding the unindexed regions and $10.18 \%$ including unindexed regions. Note that there are retained austenite islands buried inside both the martensite and ferrite regions. Hence, four distinct types of phase distribution are noted based on the SEM and EBSD results, namely: ferrite, martensite laths, retained austenite surrounded by martensite regions, and retained austenite surrounded by ferrite regions.

The average bulk compositions of the ferrite, martensite, and retained austenite phase regions measured using APT are given in Table I (weight percent in the first five rows and atom percent in the last five rows). Notice that ferrite had the lowest $\mathrm{C}$ and $\mathrm{Mn}$ concentrations, but was enriched with $\mathrm{Si}$; however, the Si concentration in ferrite was still lower than that in retained austenite 2. Martensite has a much lower $\mathrm{C}$ concentration relative to retained austenite, but it is higher relative to ferrite. Three regions of retained austenite were analyzed. The first two were retained austenite islands in between martensite regions (identified as retained austenite 1 and 2) and the third was two adjoining retained austenite regions surrounded by ferrite (identified as retained austenite 3 and 4). The retained austenite has the highest $\mathrm{C}$ concentration relative to ferrite or martensite. In addition, the retained austenite surrounded by ferrite has a lower $\mathrm{C}$ concentration relative to retained austenite surrounded by martensite. This is because the ferrite matrix has a lower inherent $\mathrm{C}$ concentration compared with martensite; hence, $\mathrm{C}$ partitioning during Q\&P processing was limited in the extent to which it enriched the retained austenite surrounded by ferrite with $\mathrm{C}$.

The APT reconstructions from the ferrite phase in Figs. 1c, d, e, and $f$ show the distribution of the individual elements $\mathrm{Fe}, \mathrm{C}, \mathrm{Mn}$, and $\mathrm{Si}$, all of which appear to be fairly uniformly distributed.

Two different tempered martensite regions revealed two distinct types of microstructure: lathlike carbide phases and discrete carbide precipitates 

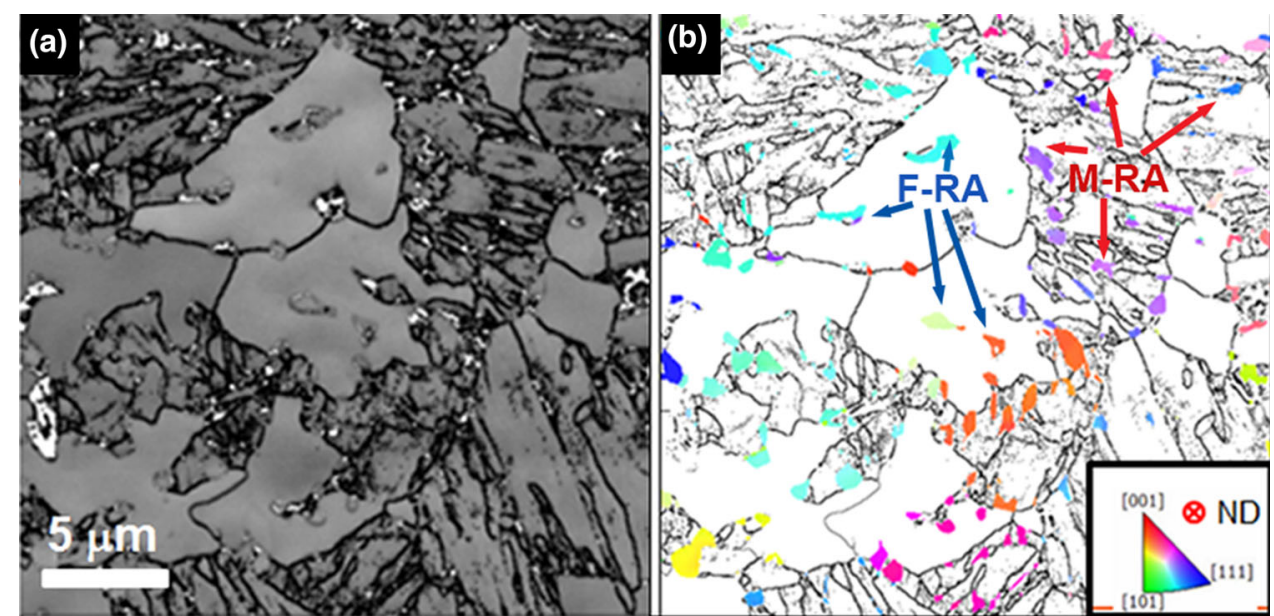

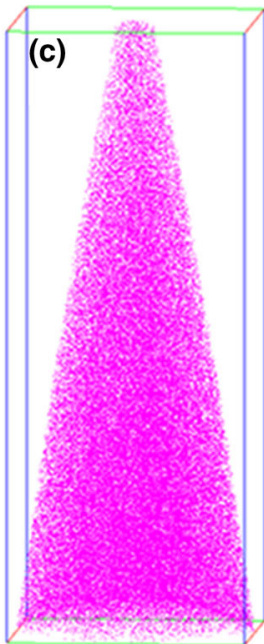

$20 \mathrm{~nm} \mathrm{Fe}$

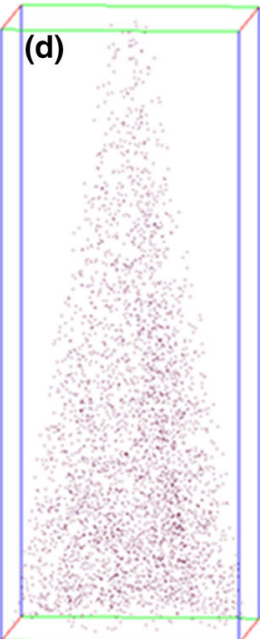

C

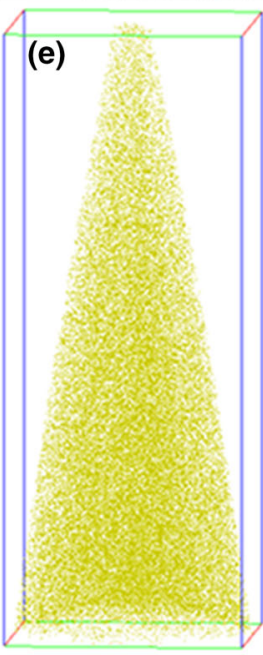

$\mathrm{Mn}$

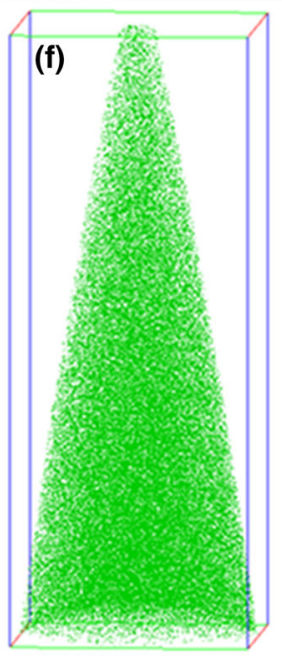

Si

Fig. 1. (a) SEM BSE image showing the overall microstructure of QP980 steel. (b) EBSD image of the same area identifying the distribution and orientation of retained austenite in ferrite and martensite. (c-f) Distribution of Fe, C, Mn, and Si in the ferrite phase of QP980 steel from APT results.

approximately $10 \mathrm{~nm}$ in size. Figures $2 \mathrm{a}, \mathrm{b}, \mathrm{c}, \mathrm{d}$, and e show the APT reconstruction of martensite regions with two intersecting carbide phases with plate-like shape. The average compositional profile as a function of the distance to a 12 at.\% C isocomposition surface, which defines the interface between the lath carbides and martensite regions, is shown in Fig. 2f. The lath-like carbides had close to 25 at.\% $\mathrm{C}$ and 75 at.\% Fe, along with $\mathrm{Mn}$ and $\mathrm{Si}$ depletion, directly corresponding to $\theta$ cementite or $\mathrm{Fe}_{3} \mathrm{C}$. This has previously been reported to form in higher C Q\&P steels. ${ }^{15}$ The APT analysis of martensite regions with isolated or discrete carbide regions is shown in Fig. 2g, h, i, j, and k. The compositional partitioning across the discrete carbide and matrix martensite phase is shown in Fig. 2l. The discrete carbide regions only appeared to have up to 20 at.\% $\mathrm{C}$ denoting under-stoichiometric $\theta$ cementite or closer to $\mathrm{Fe}_{23} \mathrm{C}_{6}$ concentration. ${ }^{15}$ For the compositional analysis of carbides given here, we assigned the mass-to-charge ratio spectra peak at $24 \mathrm{Da}$ as
$\mathrm{C}_{2}{ }^{+}$and did not consider the peak overlap with $\mathrm{C}_{4}{ }^{2+}$, although it may be a possibility. It is also to be noted that we are reporting average concentration across all carbides using a proximity histogram ${ }^{16}$ and not a size-dependent compositional profile across each carbide particle. This may introduce some variability in the measured composition of these individual carbide particles as highlighted by Martin et al. ${ }^{17}$ However in spite of this, it is clear that there are carbide precipitates in the martensitic regions in this steel, which was unexpected in this steel prior to this study. On the one hand, the nanoscale size of these carbides can play some roles in enhancing the mechanical properties of the martensite phase; on the other, the carbide precipitation can tie up $\mathrm{C}$ in the martensite matrix during the partitioning process and leaves the retained austenite less stable than desired.

The APT results of the retained austenite 1 region surrounded by martensite are shown in Fig. 3a, b, c, $\mathrm{d}$, e, and $\mathrm{f}$. The reconstruction also captured the 
interface between the retained austenite and adjacent martensite laths, denoted by the black arrows in Fig. 3a, b, c, d, and e. The compositional partitioning across the retained austenite and martensite is shown in Fig. 3f where a clear Mn (gold) and $\mathrm{C}$ (red) segregation pile-up is noted along the RAmartensite interface within a $0-4-\mathrm{nm}$ distance into the retained austenite.

A specific location with two adjacent retained austenite islands situated in the center of a ferrite region was also identified for APT analysis using EBSD (Fig. 3g). The selected retained austenite regions are denoted by the box with the dashed boundaries. The APT data from this region are shown in Fig. 3h, i, j, and k. The compositional profile across the retained austenite 3/retained austenite 4 interface is shown in Fig. 31 from which it is clear that there is an increase in $\mathrm{C}$ concentration locally at the interface while no similar segregation is observed for $\mathrm{Mn}$ and $\mathrm{Si}$. This local $\mathrm{C}$ enrichment observed across the two-RA region boundary is also highlighted using a white arrow in Fig. 3i.

\section{DISCUSSION}

Our APT results suggest both lath-like and discrete $\theta$ cementite carbides precipitate in martensite in spite of $1.4 \mathrm{wt} . \%$ Si added to suppress carbide formation. Carbides can act as strengtheners by serving as obstacles to dislocation motion during deformation, further enhancing the tensile strength, while reducing the ductility of this steel. ${ }^{18,19}$ An additional significance of carbides for Q\&P steels is that they consume $\mathrm{C}$ and thus reduce the amount of supersaturated $\mathrm{C}$ concentration in the martensite that is available for partitioning to the retained austenite islands during the partitioning step of the annealing treatment. ${ }^{9}$ Similar $\theta$ cementite carbides have been observed to form during a low-temperature partitioning step in low-carbon steels. ${ }^{20}$ It is to be noted that our observation of discrete carbides in this 0.2 wt.\% C, 1.79 wt.\% Mn QP steel is distinctly different from the discrete Mn-rich precipitates reported in a high $\mathrm{Mn}$ (12.01 wt.\%), very low C (0.01 wt.\%) steel by Dmitrieva et al. ${ }^{21}$ However, the measured concentration of carbides does agree with a recent APT study of two model steels by Kim et al., who also observed approximately 25 at.\% $\mathrm{C}$ in carbides distributed in martensite regions, although the steel had 1 wt.\% C. ${ }^{22}$

The observation of slightly different $\mathrm{C}$ contents between the different retained austenite regions (RA1 and RA2) surrounded by martensite warrants additional discussion. During the partitioning step, an retained austenite island with a large surface area interface with martensite, which is a $\mathrm{C}$ reservoir, may get a chance for greater carbon enrichment. Hence, given that there is some variability in the surface area of various retained austenite islands as evident in the EBSD results in Fig. 1b, some slight variability 

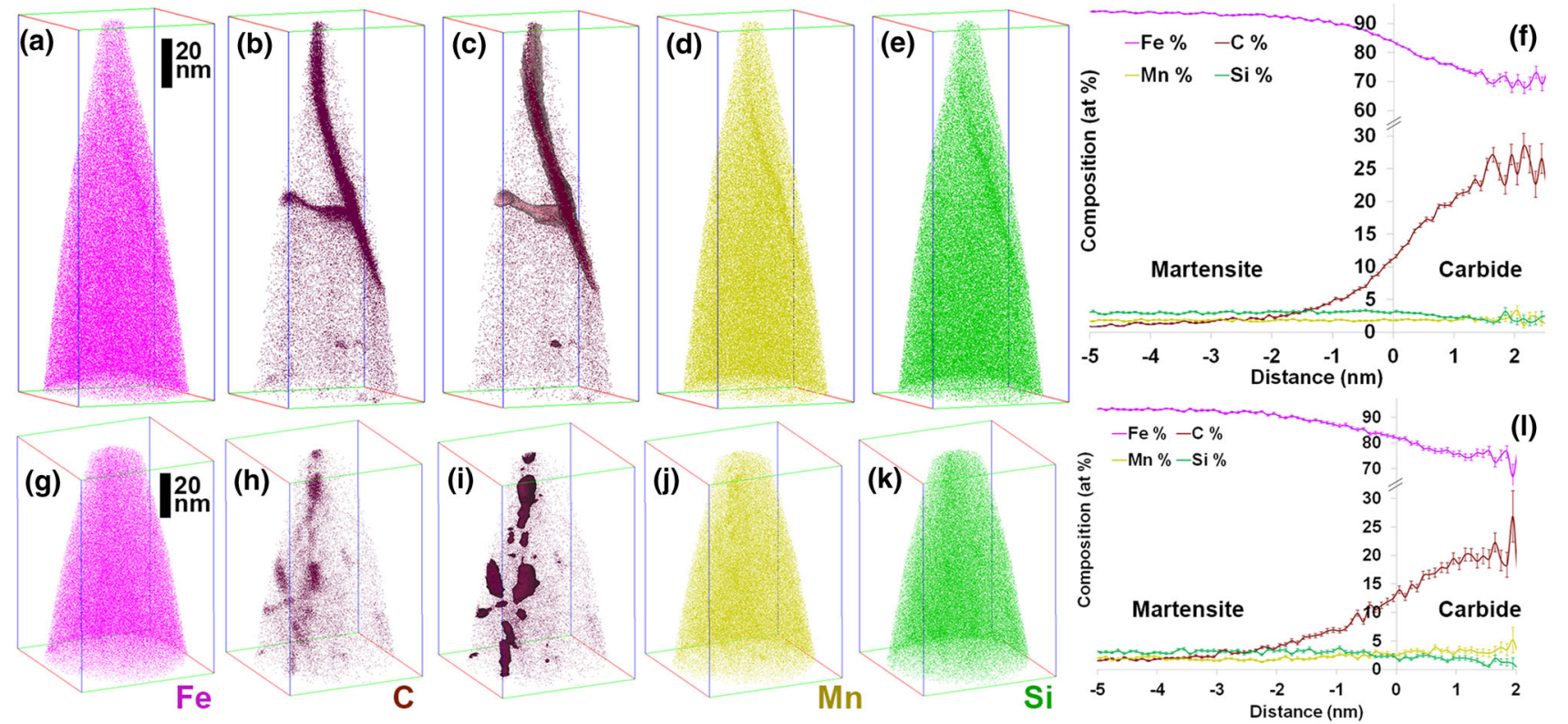

Fig. 2. APT analysis of $(a-f)$ lath and $(g-l)$ discrete $\theta$ cementite carbides inside the martensite regions. Ion distribution of Fe and $C$ shown in (a, b) and $(\mathrm{g}, \mathrm{h})$ along with a $\mathrm{C} 5$ at.\% isocomposition surface highlighting the carbide regions in (c and i). Mn and Si distribution is shown in (d, e) and (j, $\mathrm{k})$. The average solute partitioning between martensite and carbide regions is analyzed using proximity histograms in (f), (I).

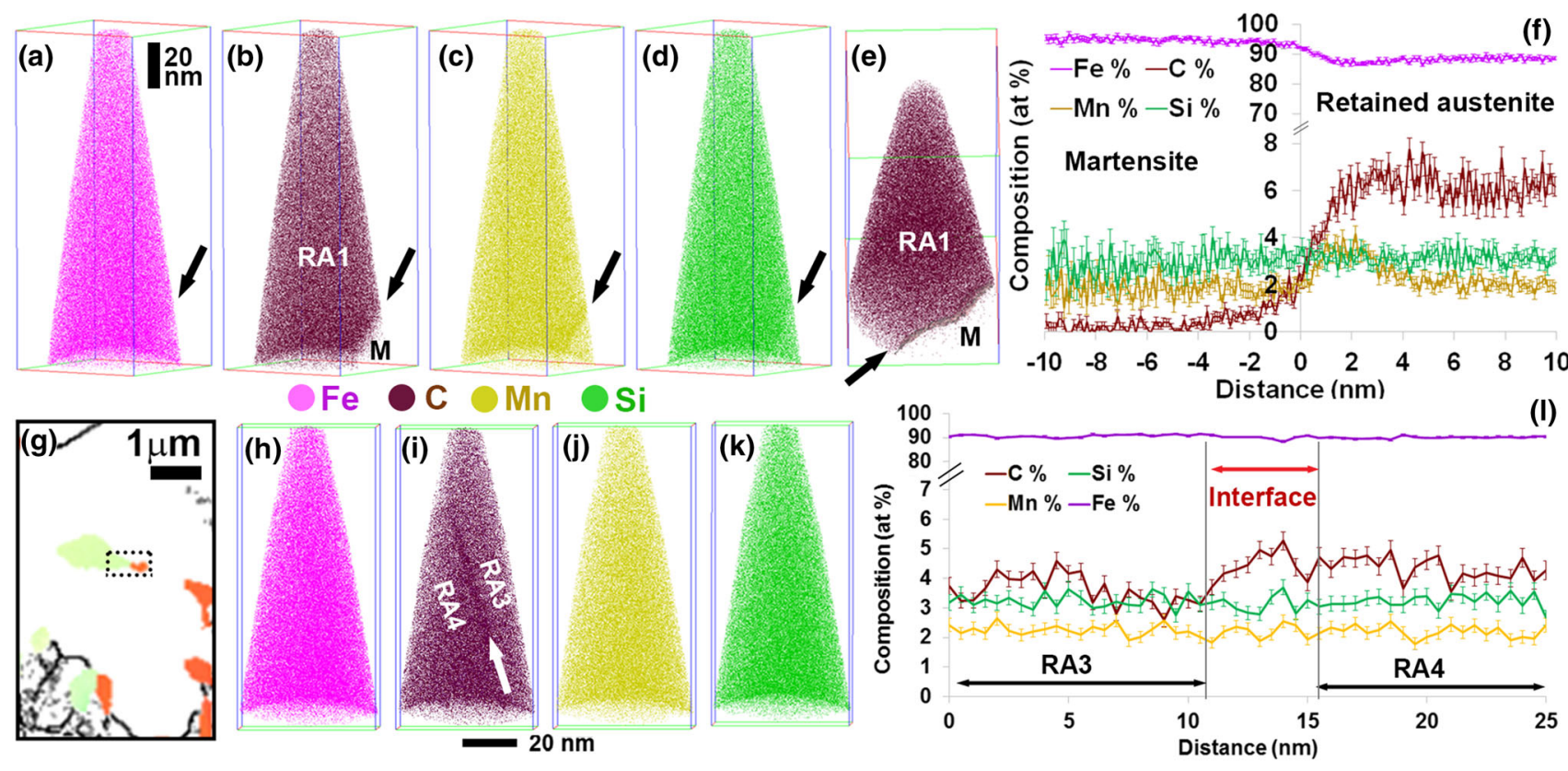

Fig. 3. (a-f) Retained austenite-martensite interface analysis by APT. The interface between retained austenite and martensite is denoted with a black arrow. (a-d) lon distribution of $\mathrm{Fe}, \mathrm{C}, \mathrm{Mn}, \mathrm{Si}$, and $\mathrm{C}$, (e) top-down view of the martensite-retained austenite interface, and (f) corresponding compositional partitioning across the retained austenite-martensite interface estimated using proximity histograms across this interface. ( $\mathrm{g}-\mathrm{l}$ ) EBSD and APT analysis of the interface between two adjacent retained austenite islands inside a ferrite region. (g) EBSD map of the specific region extracted for APT sample preparation using site-specific lift-out. The two adjacent retained austenite islands selected for the needle preparation are highlighted using a dashed rectangle. ( $\mathrm{h}-\mathrm{k}$ ) Distribution of the $\mathrm{Fe}, \mathrm{C}, \mathrm{Mn}$, and $\mathrm{Si}(\mathrm{I})$ composition profile perpendicular to the RA3/ RA4 interface.

may be anticipated in the final carbon enrichment between different retained austenite islands surrounded by martensite. Additionally, Fig. 3f suggests that $\mathrm{Mn}$ enrichment by about 2 at.\% was observed along a 4-nm width at the interface between retained austenite and the adjoining martensite. This indicates that the partitioning treatment duration and temperature may need additional tuning to allow the slower substitutional Mn diffusion to reach a uniform Mn concentration inside the retained austenite 
islands to an averaged higher value. Since C has a much higher diffusion rate into retained austenite than $\mathrm{Mn}$, it is not evident that the local Mn enrichment negatively influences the carbon partitioning during the partitioning step. However, this local Mn enrichment at the interface between the retained austenite island and martensite can progressively retard further partitioning of solutes as the partitioning process proceeds. Hence, the rate of $\mathrm{Mn}$ concentration homogenization inside retained austenite islands can limit the solute partitioning from martensite to retained austenite islands during partitioning.

No significant carbon enrichment of retained austenite islands surrounded by ferrite (which has a very low $\mathrm{C}$ concentration) occurs during the partitioning heat treatment. This explains the observation of lower overall $C$ concentration in the retained austenite islands surrounded by ferrite as shown in Fig. 3 and Table I. Interestingly, a C enrichment is noted at the interface between two adjacent retained austenite islands surrounded by ferrite in Fig. 3l. We surmise that the free volume at the interface is possibly driving this carbon enrichment; however, a more definitive explanation of this phenomenon is currently not available.

The results as such, coupled with the thermomechanical processing parameters, can be used to corroborate the elemental diffusion rates in kinetics calculations to further improve the processing parameters and performance of multiphase TRIP steels. ${ }^{23}$

\section{ACKNOWLEDGEMENTS}

This study was supported, in part, by the Department of Energy under Cooperative Agreement Number DE-EE0005976, with the United States Automotive Materials Partnership LLC (USAMP). Oak Ridge National Laboratory is operated by UTBattelle, LLC, for the US DOE under contract DEAC05-00OR22725. The DOE program name was "Integrated Computational Materials Engineering Approach to Development of Lightweight 3GAHSS Vehicle Assembly." Pacific Northwest National Laboratory (PNNL) is operated by Battelle Memorial Institute for the US Department of Energy (DOE) under Contract No. DE-AC05-76RL01830. The APT experiments were performed in Environmental Molecular Sciences Laboratory, a DOE Office of Science User Facility sponsored by the Office of Biological and Environmental Research and located at PNNL.

\section{REFERENCES}

1. P.J.G.E. DeMoor, J.G. Speer, and D.K. Matlock, AIST Trans. 7, 133 (2010).

2. E.R.P.V.F. Zackay, D. Fahr, and R. Bush, Trans. Am. Soc. Met. 60, 252 (1967).

3. W. Poling, V. Savic, L.G. Hector, Jr., A.K. Sachdev, X. Hu, A. Devaraj, X. Sun, F. Abu-Farha, Combined synchrotron $\mathrm{X}$-ray diffraction and digital image correlation technique for measurement of austenite transformation with strain in TRIP-assisted steels, Society of Automotive Engineers, SAE Paper No. 2016-01-0419 (2016).

4. J. Min, L.G. Hector, L. Zhang, J. Lin, J.E. Carsley, and L. Sun, Mater. Sci. Eng. A 673, 423 (2016).

5. X.H. Hu, X. Sun, L.G. Hector, and Y. Ren, Acta Mater. 132, 230 (2017).

6. F. Abu-Farha, X. Hu, X. Sun, Y. Ren, L.G. Hector Jr., G. Thomas, and T.W. Brown, Met. Mat. Trans. A 49, 25832696 (2018)

7. J.G. Speer, F.C.R. Assunção, D.K. Matlock, and D.V. Edmonds, Mater. Res. 8, 417 (2005).

8. B.C. De Cooman and J.G. Speer, Steel Res. Int. 77, 634 (2006).

9. Y. Toji, G. Miyamoto, and D. Raabe, Acta Mater. 86, 137 (2015).

10. Y. Toji, H. Matsuda, M. Herbig, P.-P. Choi, and D. Raabe, Acta Mater. 65, 215 (2014).

11. J. Coryell, V. Savic, S. Mishra, L.G. Hector, Jr., Temperature Effects on the Deformation and Fracture of a Quenched-and-Partitioned Steel, Society of Automotive Engineers (SAE), Paper \#2013-01-0610 (2013).

12. V. Savic, L.G. Hector, Jr., H. Singh, M. Paramasuwom, U. Basu, A. Basudhar, N. Stander, Integrated Computational Materials Engineering Approach to Development of Lightweight Third Generation Advanced High-Strength Steel (3GAHSS) Vehicle Body Structure, Society of Automotive Engineers, SAE Paper No. 2018-01-1026 (2018).

13. A. Devaraj, D.E. Perea, J. Liu, L.M. Gordon, T.J. Prosa, P. Parikh, D.R. Diercks, S. Meher, R.P. Kolli, Y.S. Meng, and S. Thevuthasan, Int. Mater. Rev. 63, 68 (2018).

14. E. De Moor, S. Lacroix, A.J. Clarke, J. Penning, and J.G. Speer, Metall. Mater. Trans. A 39, 2586 (2008).

15. G.A. Nematollahi, J. von Pezold, J. Neugebauer, and D. Raabe, Acta Mater. 61, 1773 (2013).

16. O.C. Hellman, J.A. Vandenbroucke, J. Rüsing, D. Isheim, and D.N. Seidman, Microsc. Microanal. 6, 437 (2002).

17. T.L. Martin, A. Radecka, L. Sun, T. Simm, D. Dye, K. Perkins, B. Gault, M.P. Moody, and P.A.J. Bagot, Mater. Sci. Technol. 32, 232 (2016).

18. G. Jha, S. Das, S. Sinha, A. Lodh, and A. Haldar, Mater. Sci. Eng. A 561, 394 (2013).

19. J. Fu, G. Li, X. Mao, and K. Fang, Metall. Mater. Trans. A 42, 3797 (2011).

20. M.J. Santofimia, L. Zhao, and J. Sietsma, Metall. Mater. Trans. A 42, 3620 (2011).

21. O. Dmitrieva, D. Ponge, G. Inden, J. Millán, P. Choi, J. Sietsma, and D. Raabe, Acta Mater. 59, 364 (2011).

22. B. Kim, J. Sietsma, and M.J. Santofimia, Mater. Des. 127, 336 (2017).

23. K.S. Choi, Z. Zhu, X. Sun, E. De Moor, M.D. Taylor, J.G. Speer, and D.K. Matlock, Scripta Mater. 104, 79 (2015). 